\title{
Synoptic to Microscale Processes Affecting the Evolution of a Cold-Air Pool in a Northern New England Forested Mountain Valley
}

\author{
ERIC P. KELSEY \\ Department of Atmospheric Science and Chemistry, ${ }^{a}$ Plymouth State University, Plymouth, \\ and Mount Washington Observatory, North Conway, New Hampshire \\ Matthew D. Cann, Kevin M. Lupo, And Liana J. HadDad \\ Department of Atmospheric Science and Chemistry, ${ }^{a}$ Plymouth State University, Plymouth, \\ New Hampshire
}

(Manuscript received 1 December 2017, in final form 12 February 2019)

\begin{abstract}
The formation of katabatic winds and pooling of cold air in mountain valleys impact air quality, precipitation type, and local ecosystem functions. Much is still poorly understood about the multiscale interaction of processes in a mature mixed-hardwood forest that cause the formation and evolution of cold-air pools (CAPs). Processes involved in the evolution of a CAP in the Hubbard Brook Experimental Forest valley in New Hampshire were investigated during a field campaign on 4-5 November 2015. Vertical profiles of temperature and humidity were measured along a 150-m-long tethered balloon in the center of the valley and were compared with temperature and wind observations on the surrounding slopes to identify and assess the impacts of multiscale processes on a CAP. A CAP formed rapidly during the afternoon of 4 November and attained its maximum depth of $\sim 150 \mathrm{~m}$ by sunset. This maximum depth is likely a result of the topography of the valley. Warm-air advection (WAA) occurred during the second half of the night at high elevations, and warm air mixed downward into the valley. As a result, the vertical thermal gradient strengthened and static stability increased, which allowed the lowest part of the CAP to continue to radiatively cool while the upper part of the CAP was warmed and eroded by the WAA. Results suggest that the canopy acts as the primary cooling surface for air at night, which causes split katabatic flow: cold and fast flow above canopy and warmer and slower flow below canopy. Understanding these processes in sloped forests has implications for eddy covariance research and montane microclimates.
\end{abstract}

\section{Introduction}

Interactions between cold-air pools (CAPs) and the atmosphere above can act to strengthen or erode the CAP, affecting surface temperatures and transport of hazardous pollutants. CAPs, quasi-stagnant layers of stably stratified air inherently colder than the air overlying them, are bound by local topography, including factors such as basin width, surrounding mountain height, slope angle, and local air drainage pathways, all of which affect the formation and maintenance of CAPs (Katurji and Zhong 2012). CAPs are defined by strong low-level

\footnotetext{
${ }^{a}$ The Atmospheric Science Program of Plymouth State University is now a part of the Judd Gregg Meteorology Institute.
}

Corresponding author: Eric P. Kelsey, ekelsey2@plymouth.edu inversions (i.e., high stability) that inhibit the vertical mixing of air and can lead to significant impacts on health, safety, business, and the environment. In urban environments, the stability of CAPs trap air pollution near the surface, which leads to degradation of air quality and increased respiratory problems, such as asthma (Malek et al. 2006; Whiteman et al. 2014; Wolf et al. 2014). Liquid hydrometeors descending into subfreezing CAPs can result in freezing rain, which poses a high safety risk for most transportation modes. The strength of CAPs plays a role in the duration of cold-air damming and freezing rain events in mountain valleys (Simms 2017). The height and strength of the inversion can impact snowmaking at ski resorts (Steiger and Mayer 2008). Further, quantifying the effects of forest canopy on surface temperatures and humidity is crucial to understanding CAP impacts on forest ecosystem health and management, as well as carbon 
dioxide budgets (Bowling et al. 2005; Sun et al 2006; Pypker et al. 2007; Kiefer and Zhong 2013).

CAPs can either be defined as diurnal, forming overnight and eroding the subsequent morning, or persistent, which can last several days or longer (Whiteman et al. 2001). It is generally understood that diurnal CAPs can form under clear skies, high pressure, and when synoptically driven winds are weak (Iijima and Shinoda 2000; Clements et al. 2003). A diurnal CAP is formed by two processes: radiational cooling at the valley floor and downslope cold airflow (katabatic winds) due to net radiative heat loss on the valley sidewalls (Kiefer and Zhong 2013). Energy budget calculations for individual case studies (Bodine et al. 2009) and model simulations (Schmidli and Rotunno 2010; Vosper et al. 2014) indicate that katabatic winds deepen the CAP by adding layers to the top of the CAP and contribute significantly to down-valley drainage flows.

The period in which diurnal CAPs typically form is sometimes referred to as the early evening transition (EET; Acevedo and Fitzjarrald 2001). The EET is a period during which surface state variables exhibit larger variations in the first $2 \mathrm{~h}$ than in the remaining overnight period (Gustavsson et al. 1998; Acevedo and Fitzjarrald 2001). This transitional period is most noticeably defined by an increase in surface specific humidity, the development of an inversion at the top of the CAP, and a decrease in turbulent activity. The EET is generally when a CAP gains intensity at the fastest rate of the night as surface temperatures plummet and air temperatures in the residual layer remain steady. On nights when the CAP is not disturbed by other processes, the nocturnal minimum surface temperature is largely determined by the EET (Acevedo and Fitzjarrald 2001).

Dorninger et al. (2011) describes how upper and lower disturbances can impact CAP depth and intensity at any time. A lower disturbance (e.g., back-radiation from clouds, fog formation) originates at the surface and propagates upward through the CAP producing a warming of $1^{\circ}-2^{\circ} \mathrm{C}$. Upper disturbances (e.g., downward turbulent mixing) are much more common than lower disturbances, and can be associated with a greater warming $\left(\sim 5^{\circ} \mathrm{C}\right)$. Upper disturbances were found to be directly related to winds and turbulence above the inversion, where strong winds may produce a warming of the upper CAP, but may not be sufficiently strong enough to completely erode the CAP. The process of layered erosion is a slow removal process in which an upper disturbance progressively removes layers of the CAP by turbulence generated in the high shear layer at the interface between the CAP and the atmosphere above.

Warm-air advection (WAA) aloft is an upper disturbance that can form or intensify a CAP or a cold dome in a cold-air damming event (Bell and Bosart 1988; Whiteman et al. 1999b; Whiteman et al. 2001; Lareau et al. 2013). If the WAA is strong enough to warm the top of the CAP, but not warm effectively to the surface, the CAP will intensify. Relative contributions to CAP intensity due to WAA have not been studied thoroughly and must be better understood to accurately predict how long it will take layered turbulent erosion to remove a persistent CAP or cold dome. This erosion process is very important for damaging freezing rain events, since a strong, persistent cold dome is necessary to produce substantial ice accretion.

In this paper, we investigate the evolution of a CAP that was affected by WAA in the shallow forested valley of the Hubbard Brook Experimental Forest (HBEF) in New Hampshire based on observations taken during an intensive observation field study. We use the observations to evaluate processes driving CAP development and dissipation, the evolution of CAP stability, limitations to CAP depth, and we speculate about the physical mechanisms driving CAP perturbations throughout the night. We also evaluate the impact of a mature mixed-hardwood forest on katabatic wind processes and the low-level temperature and wind profiles.

\section{Data and methods}

HBEF is a 3160-ha reserve owned and managed by the USDA Forest Service Northern Research Station, located in Grafton County, New Hampshire, within the White Mountain National Forest (Fig. 1). HBEF is a grain scoop-shaped topographic feature with a relatively narrow opening on its eastern border with a minimum elevation of $250 \mathrm{~m}$ where it opens to the north-south-oriented Pemigewasset River valley. A second low point $(600 \mathrm{~m})$ in the bounding ridgeline is located in the northwest corner, and the highest point, Mount Kineo $(1015 \mathrm{~m})$, is located $3 \mathrm{~km}$ due south of this low point. HBEF is composed of a predominantly 100-year-old second-growth northern hardwood-sprucefir forest and yellow birch variant.

An intensive observation period (IOP) was performed in HBEF on 4-5 November 2015 to study the evolution of a diurnal CAP. Sunset and sunrise times at HBEF were 2135 UTC 4 November and 1127 UTC 5 November, respectively. The authors arrived at HBEF at 1900 UTC to deploy instrumentation. A standard weather balloon was moored by a $150-\mathrm{m}$ tether and attached to a bridge approximately $4 \mathrm{~m}$ over the Hubbard Brook at $\sim 453 \mathrm{~m}$ MSL (Fig. 1), and it began recording observations at 2015 UTC. The tethered-balloon site (Fig. 1) is located in a narrow part of the valley that becomes broader $1 \mathrm{~km}$ downstream and has an $\sim 600 \mathrm{~m}$ MSL plateau (approximately the height of the highest datalogger on the tethered balloon) on the north side of the observation site. The bridge has a wooden 


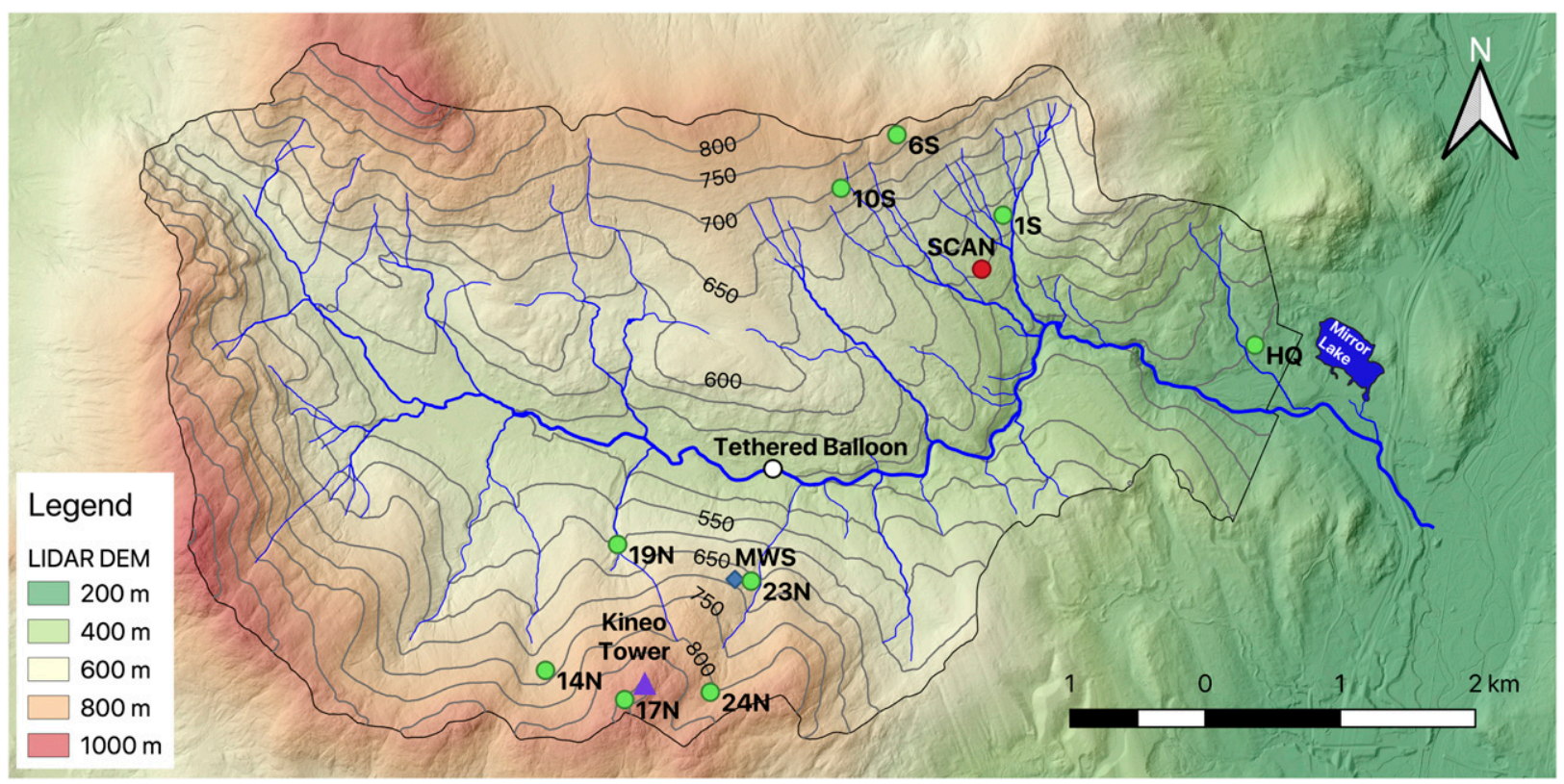

FIG. 1. HBEF site map with weather stations. Wind data were recorded at site $1 \mathrm{~S}$ and the SCAN site, Kineo tower, MWS, and Pierce Laboratory Headquarters Building (HQ). The base image was created by M. Martin.

bed and is bordered with standard anodized aluminum guard rails, to which the tether was tied. Mean canopy height surrounding the bridge is $\sim 15-20 \mathrm{~m}$. Deciduous trees in the mixed forest had shed all leaves in the upper forest canopy while some dead foliage remained in the understory on smaller trees, especially American beech. Twenty-seven HOBO Pendant temperature dataloggers (hereinafter datalogger) were attached at 5-m intervals along the tether, starting at $5 \mathrm{~m}$ above bridge level (ABL) to obtain a high-resolution temperature profile of the CAP. Four HOBO U23 Pro, version 2, dataloggers (hereinafter U23), which record temperature and relative humidity, were placed at 1.5-, 50-, 100-, and 150-m along-tether heights to measure the moisture profile of the CAP. An additional HOBO Pendant temperature datalogger was placed at $1.5 \mathrm{~m}$ AGL approximately $25 \mathrm{~m}$ north of the bridge in a mixed-forest environment to confirm that data at the bridge were representative of the forested HBEF valley bottom. All dataloggers recorded observations every 30 s and were analyzed in this study using a 10-min-movingaverage filter to remove high-frequency variability.

Because the first and last $\sim 3 \mathrm{~h}$ of the IOP were anticipated to occur in the presence of solar radiation (albeit weak), radiation shields for all dataloggers were developed that both minimized direct solar heating and were light enough collectively to not exceed the load-bearing limit of the balloon. Multiple shielding techniques were tested during 10-13 October 2015 by placing shielded and unshielded dataloggers on a string $\sim 1.5 \mathrm{~m}$ above the roof of the Judd Gregg Meteorology Institute (Plymouth State
University), with specific focus on the behavior of the dataloggers during sunrise periods of 11,12 , and 13 October. These periods were generally characterized by clear and nearly calm conditions. It was found that the most efficient design to shield the dataloggers from direct sunlight and minimize the weight carried by the tethered balloon was to wrap them in a layer of lightweight aluminum foil. Temperature was validated using a datalogger placed in a standard Stephenson shelter. After applying a 10-minmoving-average filter to the temperature time series, the method of aluminum foil wrapping resulted in a mean bias of $+0.41^{\circ} \mathrm{C}$ for the $2.5 \mathrm{~h}$ after sunrise when winds remained $<2 \mathrm{~m} \mathrm{~s}^{-1}$ and the datalogger was exposed to sunshine. This bias decreased to $+0.15^{\circ} \mathrm{C}$ when the wind was $\geq 2 \mathrm{~m} \mathrm{~s}^{-1}$ during the testing period with sunshine.

To quantify the variability between individual instruments, all dataloggers were placed in a controlled environment at approximately $20^{\circ} \mathrm{C}$ for $12 \mathrm{~h}$ after the field campaign. Residual temperatures relative to the mean temperature of all dataloggers were computed for each individual logger at each 30 -s time step. A mean bias was computed from the errors at all time steps during the 12-h period for each individual datalogger. These loggerspecific mean biases while in the control environment represent an estimation of the systematic error of each instrument (relative to the mean temperature of all dataloggers), and are applied as a corrective adjustment to the dataloggers' temperature measurements during the CAP observation period. The $145-\mathrm{m}$ along-tether datalogger continued to report a temperature $1^{\circ}-2^{\circ} \mathrm{C}$ colder than the 
140- and 150-m along-tether temperatures after bias correction, resulting in an apparent persistent unstable layer between 140 and $145 \mathrm{~m}$ that does not appear to be physically reasonable. Therefore, the $145-\mathrm{m}$ along-tether data point was removed from the analysis.

At times during the IOP, the wind moved the tethered balloon off zenith enough to significantly lower the height of the dataloggers. To estimate the height of the dataloggers at these times, LED lights attached to the balloon tether were used in conjunction with a clinometer to determine the angle above the horizon of the 150-, 100-, 50-, and $25-\mathrm{m}$ along-tether points. The tether angle was continuously monitored, and observations were recorded hourly and when large changes of the balloon angle $\left(\sim 10^{\circ}\right)$ were observed. Observed tether angles were interpolated spatially to 5-m along-tether resolution to match the position of the dataloggers. It was noted by the observers during the IOP that the tether angle did not vary significantly between 1.5 and $25 \mathrm{~m}$ along the tether. Thus, the observed $25-\mathrm{m}$ along-tether angle was also assigned to dataloggers at the 20-, 15-, 10-, 5-, and 1.5-m along-tether positions. Observed tether angles were interpolated temporally to match the 30 -s resolution of the dataloggers. Heights of the dataloggers above bridge level were determined using along-tether distance and tether angles. Because of the swaying of the balloon in the stronger winds that occurred after $\sim 0430$ UTC, the elevation angle of the moored balloon above the horizon was estimated to vary by up to $\pm 10^{\circ}$ between observations. The implications for the estimated height of the dataloggers in the vertical temperature profile are included in section $3 b$.

U23 dewpoint temperature was interpolated linearly to the along-tether positions of each datalogger. Vapor pressure $e$, mixing ratio $w$, saturation mixing ratio $w_{s}$, and virtual temperature $T_{v}$ were computed for each datalogger position. A combination of temperature and moisture observations along the profile and manual observations of atmospheric pressure at $1.5 \mathrm{~m}$ above ground level using a handheld Kestrel 3000 were used to determine pressure at each height along the tethered balloon and to compute values of virtual potential temperature $\theta_{v}$ through the depth of the profile. Vertical profiles of virtual potential temperature from the tethered balloon were generated for every 30-s time step during the IOP.

The cold-pool intensity (CPI), defined in Mahrt and Heald (2015), is adopted and modified here for the top and bottom of the CAP:

$$
\mathrm{CPI}=\theta_{T}-\theta_{B},
$$

where $\theta_{T}$ is the potential temperature at or near the top of the CAP and $\theta_{B}$ is the potential temperature at the bottom of the CAP. Static stability was computed via the Brunt-Väisälä frequency:

$$
N=\left(\frac{g}{\theta_{v}} \frac{\partial \theta_{v}}{\partial z}\right)^{1 / 2},
$$

where $N$ is the Brunt-Väisälä frequency $\left(\mathrm{s}^{-1}\right), g=$ $9.8 \mathrm{~m} \mathrm{~s}^{-1}, \bar{\theta}_{v}$ is the CAP mean virtual potential temperature $(\mathrm{K}), \partial \theta_{v}$ is the virtual potential temperature difference from the CAP top to the surface $(\mathrm{K})$, and $\partial z$ is the height of the CAP $(\mathrm{m})$.

The U.S. Forest Service measures temperature at 23 sites in HBEF in clearings of $\sim 40$-m diameter, classified here by sensor number and direction that the slope faces (e.g., $\mathrm{N}=$ north-facing slope), and at a Soil Climate Analysis Network site (SCAN) operated by the National Resource Conservation Service (NRCS) in a clearing of $\sim 25$-m diameter (Fig. 1). Automated measurements of wind speed and direction are taken every $15 \mathrm{~min}$ at sites $1 \mathrm{~S}, 17 \mathrm{~N}$, and HQ (Pierce Laboratory: HBEF Headquarters) and every hour at the SCAN site. A Sutron mobile weather station (hereinafter MWS) was placed in the forest near site $23 \mathrm{~N}$ (Fig. 1) to establish a wind measurement directly uphill from the tethered balloon and to compare temperature, humidity, and wind undercanopy with the $\sim 40-\mathrm{m}$ opening nearby. The authors measured temperature, dewpoint temperature, and wind speed and direction in the clearings and adjacent forest using a Kestrel 3000 at sites $1 \mathrm{~S}$ and $23 \mathrm{~N}$ approximately every $3 \mathrm{~h}$ starting at $\sim 2200$ UTC and hourly at the bridge. Temperature and humidity were measured by slinging the Kestrel until an equilibrium temperature was reached, and wind was recorded every $5 \mathrm{~s}$ for a 5 -min period.

General synoptic-scale weather conditions and shortrange forecast conditions were examined prior to the onset of the IOP. The potential influence of background synoptic-scale weather conditions on a CAP were assessed at the conclusion of the IOP using initial conditions from the North American Mesoscale Forecast System (NAM) model at 6-h intervals from 1800 UTC 4 November through 1200 UTC 5 November from the National Centers for Environmental Information. All datasets used and their usage are listed in Table 1.

\section{Results}

\section{a. Synopsis}

Conditions during the afternoon of 4 November were clear, with a 500-hPa ridge approaching from the west. At the surface, a ridge axis extended northward through HBEF from an area of high pressure centered over the 
TABLE 1. Summary of instrumentation and data sources used for analysis of the 4-5 Nov 2015 HBEF IOP. Asterisks denote preexisting observation platforms and data sources outside those specifically configured for use during this IOP.

\begin{tabular}{|c|c|c|c|}
\hline Obs platform & Frequency & Type(s) & Usage \\
\hline HOBO Pendant dataloggers & $30 \mathrm{~s}$ & Temperature & $\begin{array}{l}\text { Temperature along the tethered } \\
\text { balloon and in forested areas } \\
\text { adjacent to the bridge and site-1S } \\
\text { clearing }\end{array}$ \\
\hline HOBO U23 Pro v2 dataloggers & $30 \mathrm{~s}$ & $\begin{array}{l}\text { Temperature and relative } \\
\text { humidity }\end{array}$ & $\begin{array}{l}\text { Temperature and moisture along the } \\
\text { tethered balloon; moisture obs were } \\
\text { used with Kestrel and clinometer } \\
\text { obs to compute } \theta_{v} \text { at each datalogger }\end{array}$ \\
\hline Clinometer (analog) & $\sim 1 \mathrm{~h}$ and $>10^{\circ}$ variations & $\begin{array}{l}\text { Tether angle at } 150-, 100-, 50- \\
\text { and } 25-\mathrm{m} \text { along-tether } \\
\text { positions }\end{array}$ & $\begin{array}{l}\text { Tilt angle of tethered balloon (i.e., } \\
\text { datalogger height); used with } \\
\text { Kestrel and datalogger obs to } \\
\text { compute } \theta_{v} \text { at each datalogger }\end{array}$ \\
\hline Kestrel 3000 & $\begin{array}{l}\sim 1 \mathrm{~h}(\text { balloon }), \\
\text { (b) } \sim 3 \mathrm{~h}(\text { site } 1 \mathrm{~S}) \\
\text { (c) } \sim 3 \mathrm{~h}(\text { site } 23 \mathrm{~N})\end{array}$ & $\begin{array}{l}\text { Temperature, dewpoint, } \\
\text { pressure, and wind } \\
\text { speed }\end{array}$ & $\begin{array}{l}\text { Obs at and under the bridge and in } \\
\text { site-23N and site-1S clearings and } \\
\text { adjacent forested areas; pressure } \\
\text { obs at the bridge were used to } \\
\text { compute } \theta_{v} \text { at each datalogger }\end{array}$ \\
\hline Sutron MWS & $30 \mathrm{~s}$ & $\begin{array}{l}\text { Temperature, dewpoint, } \\
\text { pressure, wind speed, and } \\
\text { wind direction }\end{array}$ & $\begin{array}{l}\text { Continuous, high-frequency obs on a } \\
\text { forested slope adjacent to the site- } \\
23 \mathrm{~N} \text { clearing }\end{array}$ \\
\hline *USDA-FS sites & $15 \mathrm{~min}$ & $\begin{array}{l}\text { Temperature, wind speed, and } \\
\text { wind direction }\end{array}$ & $\begin{array}{l}\text { Continuous obs in multiple clearings } \\
\text { and at multiple elevations along } \\
\text { both the north- and south-facing } \\
\text { slopes }\end{array}$ \\
\hline *NRCS-SCAN site & $1 \mathrm{~h}$ & $\begin{array}{l}\text { Temperature, wind speed, and } \\
\text { wind direction }\end{array}$ & $\begin{array}{l}\text { Continuous obs in multiple clearings } \\
\text { and at multiple elevations along } \\
\text { both the north- and south-facing } \\
\text { slopes }\end{array}$ \\
\hline *NAM 218 analysis & $6 \mathrm{~h}$ & - & $\begin{array}{l}\text { Used post-IOP to identify any meso- } \\
\text { synoptic-scale influence on the } \\
\text { evolution of the nocturnal CAP }\end{array}$ \\
\hline
\end{tabular}

mid-Atlantic coast at 1800 UTC. Maximum low-level WAA on the northwest side of the ridge was located over eastern New York at 1800 UTC, $2 \mathrm{~h}$ prior to the start of the IOP. Wind at 900-hPa paralleled the thermal gradient over New Hampshire at 1800 UTC, implying negligible thermal advection at the start of the IOP (Fig. 2).

b. HBEF cold-air pool evolution: 4-5 November 2015

\section{1) 2015-2130 UTC 4 NOVEMBER: RAPID COOLING}

The tethered balloon and MWS were deployed and operating by 2015 and 2145 UTC, respectively. Katabatic winds were already flowing upon arrival to setup the MWS at site $23 \mathrm{~N}$ at $\sim 2100$ UTC when there was no direct sunlight incident on the north-facing slope. Mountain winds (i.e., wind blowing down valley) at a 5-min mean of $0.7 \mathrm{~m} \mathrm{~s}^{-1}$ commenced at the bridge at $\sim 2115$ UTC. The temperature profile indicated that a shallow 10-m-deep CAP was already in place at 2015 UTC, which may have persisted under the shelter of the partial canopy from the morning CAP, but is ultimately unknown. During 2030-2130 UTC, the CAP rapidly deepened at a rate of $\sim 100 \mathrm{~m} \mathrm{~h}^{-1}$, reaching its maximum $\sim 140$-m vertical extent at the observation site by 2130 UTC (Fig. 3). Time series of the observed temperatures along the vertical profile suggest that the cooling rate between 2015 and 2115 UTC was nearly constant through the upper $120 \mathrm{~m}$ of the vertical profile $\left(\sim 5^{\circ} \mathrm{C} \mathrm{h}^{-1}\right)$, with a slower cooling rate in the approximately $15-20 \mathrm{~m}$ nearest to the surface $\left(\sim 2^{\circ} \mathrm{C} \mathrm{h}^{-1}\right.$; Fig. 3) where cold air already existed and the aboveground biomass acted to partially trap longwave radiation.

\section{2) 2130 UTC 4 NOVEMBER-0430 UTC 5 NOVEMBER: REDUCTION OF UPPER COOLING RATE}

By 0000 UTC 5 November, the ridge axis had progressed to the east over central Maine (Fig. 2b). Wind above HBEF at $900-\mathrm{hPa}$ increased to $\sim 10 \mathrm{~m} \mathrm{~s}^{-1}$ and was no longer perpendicular to the synoptic-scale temperature gradient, implying the onset of low-level warm advection over HBEF (Fig. 2). However, the warm-air advection did not propagate downward into the HBEF valley until $\sim 0410$ UTC.

Within the valley, the 2130 UTC-0410 UTC period was characterized by a rapid reduction of the rate of cooling by $\sim 80 \%$ at the top of the CAP from $\sim 1.70^{\circ}$ to 


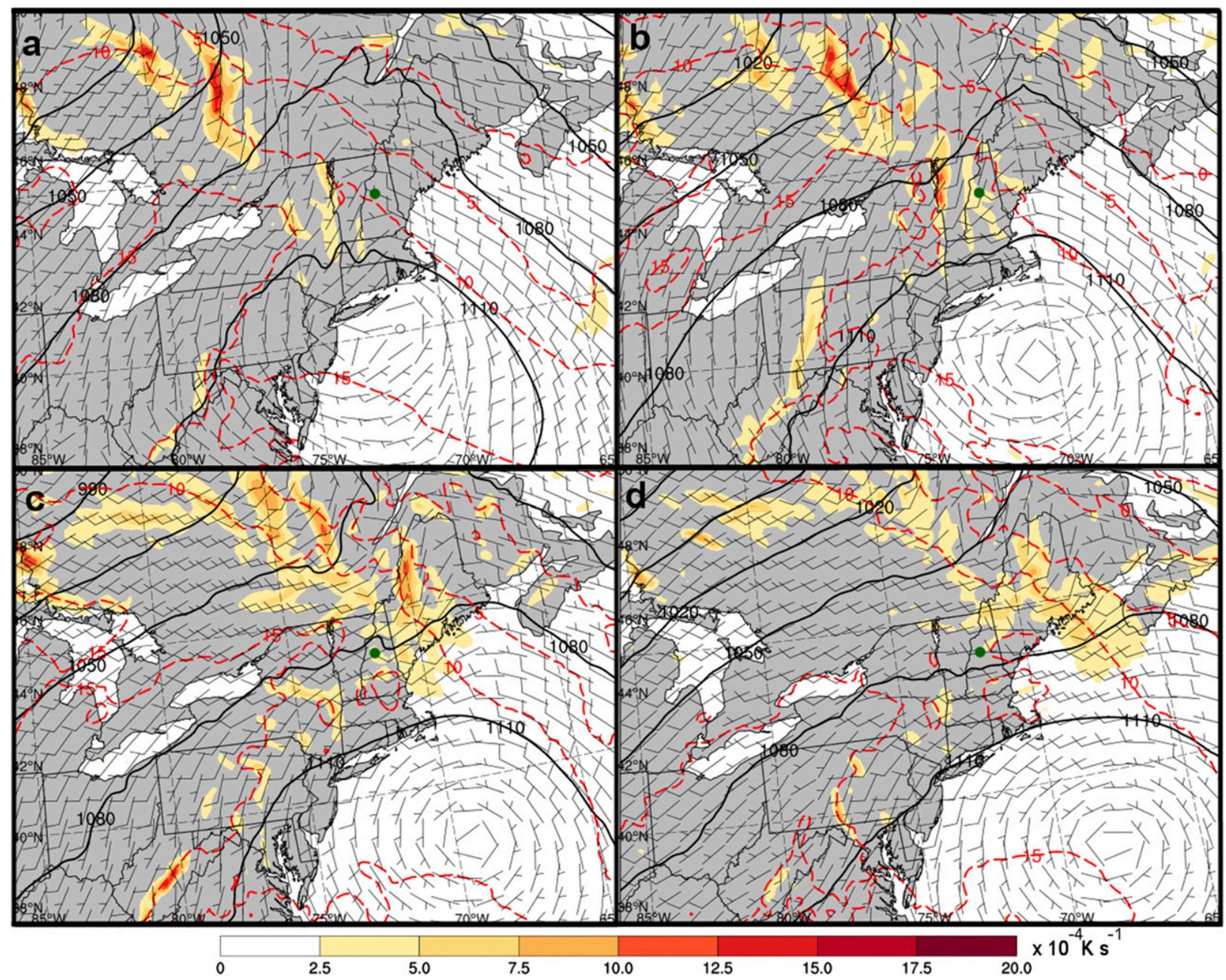

FIG. 2. From the NAM analysis, positive 900-hPa temperature advection (color shaded; $\times 10^{-4} \mathrm{~K} \mathrm{~s}^{-1}$ ), geopotential heights (black contours; $\mathrm{m}$ ), temperature (red dashed contours; ${ }^{\circ} \mathrm{C}$ ), and wind barbs (short barbs are $5 \mathrm{~m} \mathrm{~s}^{-1}$; long barbs are $10 \mathrm{~m} \mathrm{~s}^{-1}$ ) at (a) $1800 \mathrm{UTC} 4 \mathrm{Nov}$, (b) 0000 UTC 5 Nov, (c) 0600 UTC 5 Nov, and (d) 1200 UTC 5 Nov 2015. The green circle indicates the location of HBEF.

$\sim 0.3^{\circ} \mathrm{C} \mathrm{h}^{-1}$ while near the surface the rate of cooling decreased gradually from $\sim 2.5^{\circ}$ to $\sim 0.3^{\circ} \mathrm{Ch}^{-1}$. Meanwhile, the temporal evolution of the $\theta_{v}$ profiles (Fig. 4) suggest that the top of the CAP held steady at or just above $140 \mathrm{~m} \mathrm{ABL}$, which implies a balance between the volume fluxes of katabatic flow contributing to the CAP and mountain flow exiting the HBEF valley into the Pemigewasset River valley. The air in the upper part of the CAP likely originated from the reservoir of free atmospheric air above the CAP that has little temperature change at night. Free tropospheric and/or residual layer air continually feeds into the katabatic flow on the upper slopes because of continuity, is cooled along the slopes, and then flows across the upper part of the CAP. The bottom of the CAP likely maintained a relatively higher cooling rate because of its slow movement allowing it to remain in contact with the cold ground and biomass. The bottom $\sim 15 \mathrm{~m}$ of the vertical profile, the subcanopy layer, at 0430 UTC is characterized by a nearly isentropic layer that persisted for a majority of the remaining overnight period (Fig. 4) even as that layer continued to cool. The relatively sheltered setting of the forest around the bridge site may act to homogenize the air temperature via absorption and reemission of trapped longwave energy by the ground and biomass in the subcanopy, or downward airflow from above canopy could be creating this isentropic profile; more temperature, wind, and infrared radiation observations are needed to understand how this isentropic layer forms.

\section{3) 0430-0751 UTC 5 NOVEMBER: INITIAL UPPER WARMING}

By 0600 UTC, the 900-hPa ridge axis had progressed to the east of the Maine-New Brunswick border while 


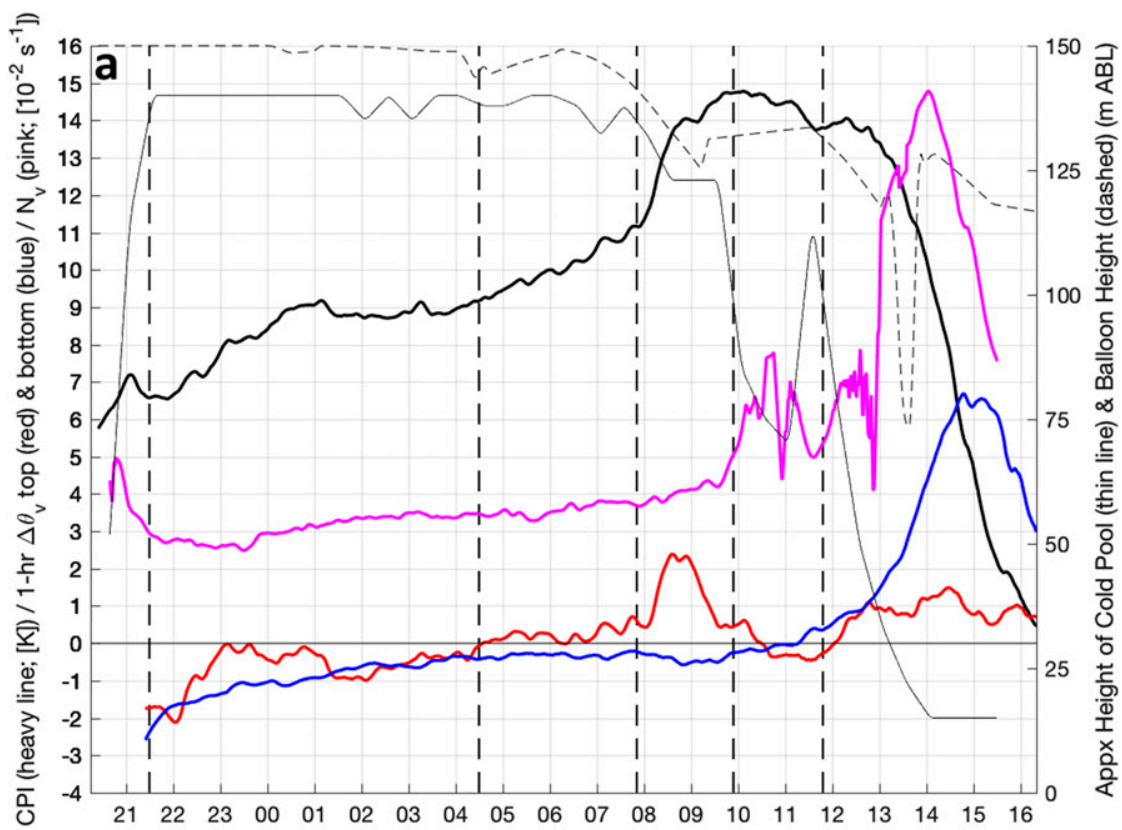

(1)

(2)

(3)

(4) (5)

(6)

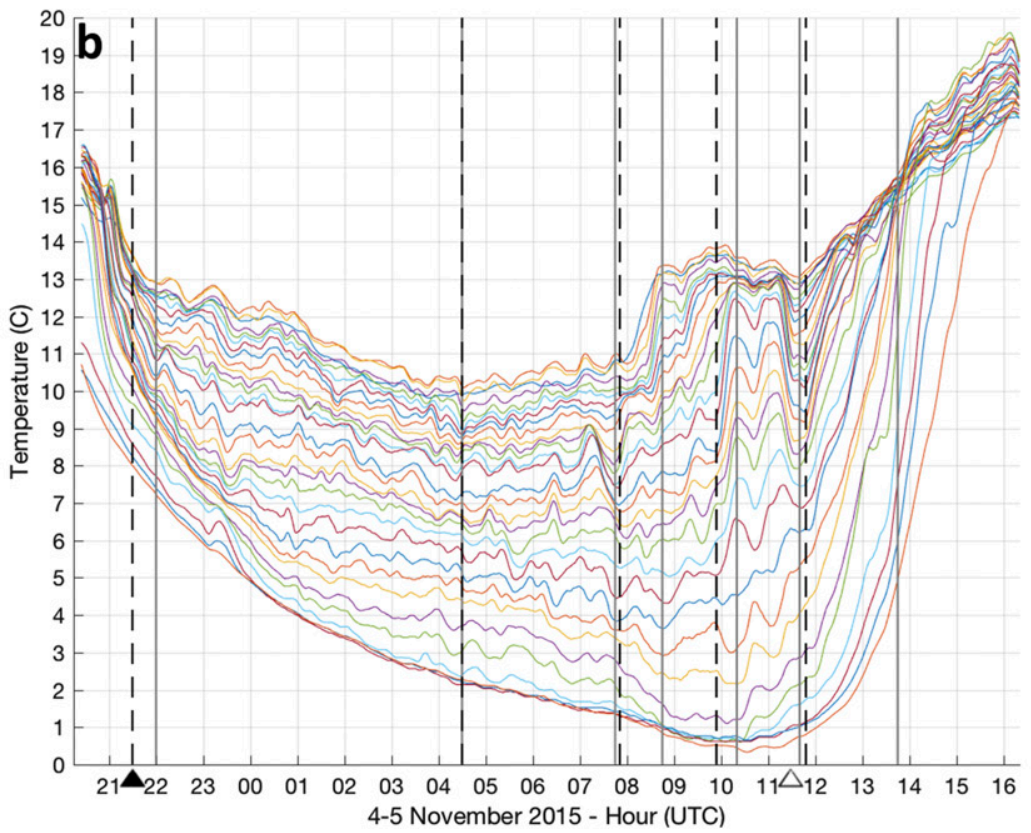

FIG. 3. (a) Time series of CPI between the top and bottom of the tethered balloon (thick black line), CAP height (thin black line), Brunt-Väisälä frequency (thick magenta line), maximum height of the balloon (thin dashed line), $1-\mathrm{h} \theta_{v}$ change at the top of the tether $(150 \mathrm{~m}$ AGL; thick red line), and 1-h $\theta_{v}$ change at the bottom of the tether (1.5 m AGL; thick blue line). (b) Time series of temperatures at all dataloggers along the tether, filtered to a 10-min moving average. Dashed black vertical lines and numbers in parentheses at the top of the plot correspond to time delineations 1-6 of section $3 \mathrm{~b}$. Gray vertical lines correspond to the vertical profiles plotted in Fig. 4, below. Filled and open triangles below the $x$ axis indicate sunset (2135 UTC) and sunrise (1127 UTC), respectively. 


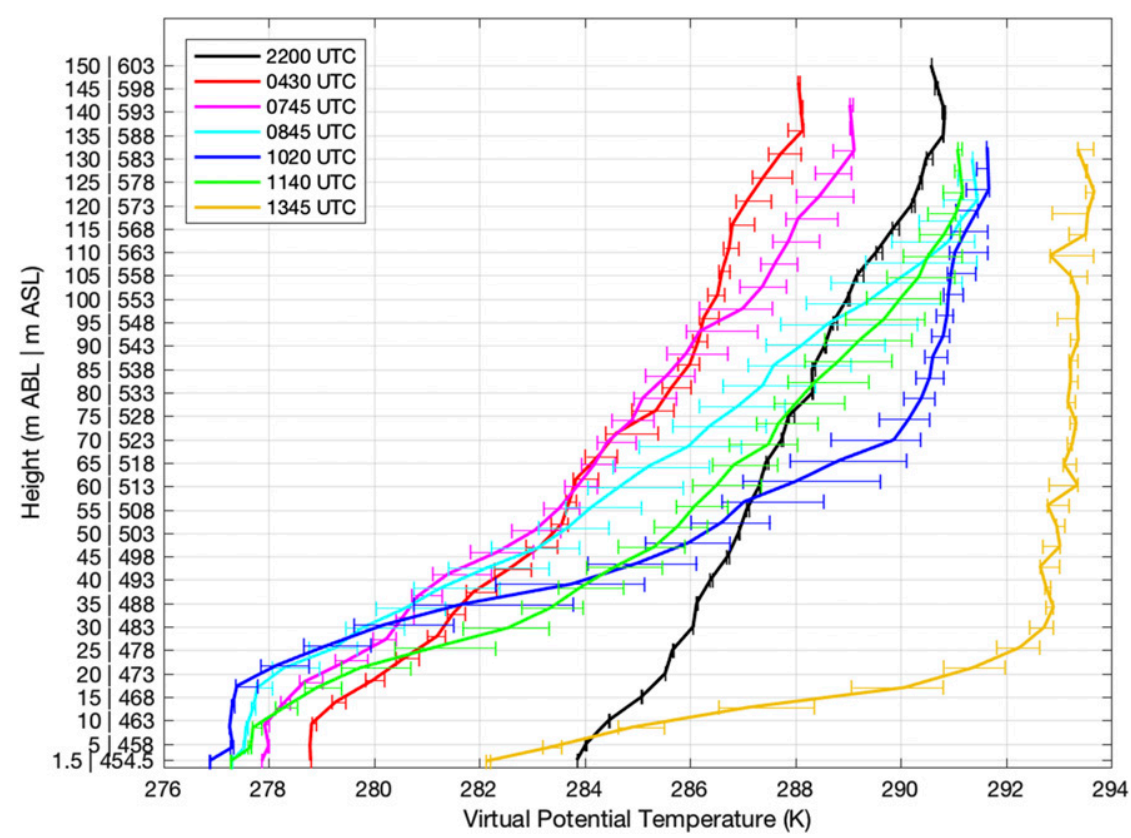

FIG. 4. Vertical profile of $\theta_{v}$ as measured by HOBO dataloggers along the tethered balloon during the IOP. Error bars are associated with $\pm 10^{\circ}$ uncertainty in the observed height of the dataloggers.

cross-isotherm west-southwesterly winds above HBEF remained $\sim 10 \mathrm{~m} \mathrm{~s}^{-1}$ (Fig. 2c). The low-level WAA that began prior to 0000 UTC over Vermont and New Hampshire continued and strengthened through 0600 UTC. The CAP underwent a second major transition during the period between 0430 and 0751 UTC 5 November, as the upper $75 \mathrm{~m}$ of the vertical profile began to experience a gradual warming (Fig. 3b).

The first change in balloon height from nearly vertical occurred at $\sim 0430$ UTC (Fig. 3a; dashed line) when the balloon drifted to the east. The onset of a westerly wind at the balloon height is supported by a $1.5 \mathrm{~m} \mathrm{~s}^{-1}$ wind speed increase between 0300 and 0600 UTC and a $\sim 0.5^{\circ} \mathrm{C}$ warming between 0500 and 0600 UTC at Mount Kineo ( $\sim 400 \mathrm{~m}$ above maximum balloon height; Fig. 5).
The increase in wind speed at the top of the CAP, initial variation in the height of the CAP (Fig. 3a), and the warming of the upper $75 \mathrm{~m}$ of the vertical profile indicate that the westerly wind and associated WAA began to affect the evolution of the CAP beginning at approximately 0430 UTC.

The 0430-0751 UTC period marked the first time during the overnight period that the hourly temperature change at the top of the tethered balloon was positive (Fig. 3a, red line). The bottom of the profile cooled at a nearly constant rate of $\sim 0.50^{\circ} \mathrm{Ch}^{-1}$ during this period (Fig. 3a, blue line). CPI increased from about $9.0^{\circ}$ to $11.0^{\circ} \mathrm{C}$ because of the concurrent upperlevel warming and low-level cooling during the period (Fig. 3a, thick black line).

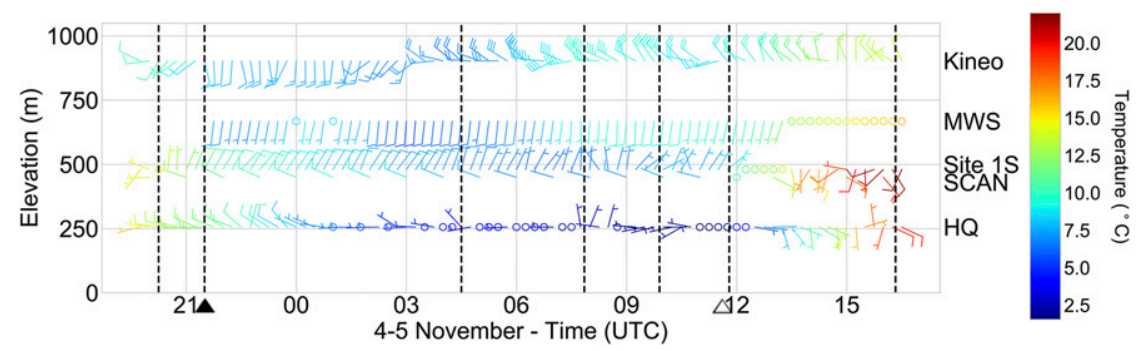

FIG. 5. Wind and temperatures at slope sites: 15-min averages for Kineo (903 m), MWS (668 m), site $1 \mathrm{~S}(480 \mathrm{~m})$, and HQ $(256 \mathrm{~m})$ and 1-h averages for SCAN $(450 \mathrm{~m})$. Kineo temperatures are from nearby site $17 \mathrm{~N}$. A full barb indicates $1 \mathrm{~m} \mathrm{~s}^{-1}$, a half barb indicates $0.5 \mathrm{~m} \mathrm{~s}^{-1}$, and an open circle indicates calm. Dashed black vertical lines correspond to time delineations $1-6$ of section $3 b$. Filled and open triangles below the $x$ axis indicate sunset (2135 UTC) and sunrise (1127 UTC), respectively. 


\section{4) 0751-0954 UTC 5 NOVEMBER: RAPID UPPER WARMING}

The most rapid warming of the top of the observed vertical profile occurred during the 2 -h period from 0751 to 0954 UTC. The upper $15 \mathrm{~m}$ of the profile warmed by $\sim 2.5^{\circ} \mathrm{C}$ during $0745-0845$ UTC, with the warming diminishing downward to the 85-m along-tether datalogger (Fig. 3b). Low-level WAA at the top of the profile, occurring in conjunction with continued cooling at the surface, increased the CPI from $\sim 11.5^{\circ}$ to $\sim 15.0^{\circ} \mathrm{C}$ during the 2-h period (Fig. 3a, thick black line). Strengthening lowlevel winds acted to tilt the tethered balloon to the east, reducing the balloon height to $\sim 125 \mathrm{~m}$ at 0910 UTC (Fig. 3a, thin dashed line). The evolution of the CAP during this period is consistent with a CAP evolving with an upper-level disturbance, as defined by Dorninger et al. (2011; see Fig. 2e).

After $\sim 0845$ UTC, the middle layers of the vertical profile experienced a rapid warming as the top of the CAP began to erode. By 0954 UTC, the upper $40 \mathrm{~m}$ of the vertical profile became nearly isentropic, suggesting turbulent mixing and/or a net drainage of CAP air reduced the depth of the CAP by $40 \mathrm{~m}$ during this 2 -h period (Fig. 3a).

\section{5) 0954-1148 UTC 5 NOVEMBER: Two TIME-LAGGED WARMING-COOLING EVENTS}

Between 0600 and 1200 UTC 5 November, the NAM analysis suggests WAA diminished over New Hampshire as 900-hPa wind speed decreased and warm-air advection diminished (Fig. 2). HBEF observations were consistent with the NAM analysis: rapid warming at the top of the vertical profile ended by 0954 UTC (Fig. 3b), and Mount Kineo temperature stopped increasing and wind speed decreased after 0800 UTC (Fig. 5).

A series of warming and cooling events occurred in the valley between 1000 and 1148 UTC. Initially, vertical mixing at the top of the CAP rapidly eroded the CAP depth another $40 \mathrm{~m}$ to $\sim 85 \mathrm{~m}$ AGL by 1100 UTC (Fig. 3b). This warming period was followed by a nearly simultaneous $\sim 2^{\circ} \mathrm{C}$ temperature increase in the upper $40 \mathrm{~m}$ of the remaining CAP (45-85 $\mathrm{m}$ AGL) between 1000 and 1030 UTC (Fig. 3b). The rapid downward propagation of warm air from the $85 \mathrm{~m}$ to the $45 \mathrm{~m}$ alongtether datalogger between $\sim 1000$ and $\sim 1005$ UTC, occurred at an average rate of $\sim 0.1 \mathrm{~m} \mathrm{~s}^{-1}$. Warming below $45 \mathrm{~m}$ lagged the upper CAP warming by about $20 \mathrm{~min}$. A subsequent $\sim 1.5^{\circ} \mathrm{C}$ cooling-warming period in the upper CAP followed between 1030 and 1130 UTC (Fig. 3b). A final cooling period of $\sim 2^{\circ} \mathrm{C}$ in the upper portion of the CAP prior to sunrise when ridge-top wind speed had decreased from its peak for $\sim 2 \mathrm{~h}$ suggests a cessation of turbulent mixing that allowed katabatic winds to increase the CAP depth to $\sim 115 \mathrm{~m}$ (Fig. 3a). This CAP depth increase is similar to the "cold-air-pool window" events described by Dorninger et al. (2011; their Figs. 2h and 7), during which rapid CAP development is observed during short calm or cloud-free "windows" within generally unfavorable overnight periods.

\section{6) 1148-1620 UTC 5 NOVEMBER: FINAL WARMING AND EROSION}

Drainage of the CAP into the Pemigewasset River valley to the east was no longer balanced by katabatic winds after sunrise, thus allowing the height of the CAP to rapidly diminish. At 1120 UTC, observers at site $1 \mathrm{~S}$ noted that the sound of moving water in Hubbard Brook was no longer audible as it was earlier in the night, but vehicles on Interstate $93(\sim 3.5 \mathrm{~km}$ to the southeast) could be heard, suggesting that the top of the CAP and associated inversion was located below the elevation of site $1 \mathrm{~S}$ and trapped the sound of the babbling brook. The observers' note is consistent with an increase in the Brunt-Väisälä frequency, a measure of static stability, at 1100 UTC (Fig. 3a, thick magenta line). The BruntVäisälä frequency rapidly increased to $\sim 0.15 \mathrm{~s}^{-1}$ after sunrise, indicating an increase in the static stability of the CAP, as the depth of the CAP decreased to $\sim 25 \mathrm{~m}$ at 1345 UTC and the CPI remained at $\sim 9 \mathrm{~K}$. Complete erosion of the CAP did not occur by the end of the IOP at 1630 UTC; colder air remained under the canopy.

\section{c. Slope observations}

The time ranges below are the same as in section $3 \mathrm{~b}$ for easy comparison, with the exception that the times from sections $3 b(4)$ and $3 b(5)$ are combined below. The titles were removed because they do not always reflect conditions on the slopes.

\section{1) 2015-2130 UTC 4 NOVEMBER}

Temperature observations in the 40-m clearings along the slopes (including the forested MWS), summit, and valley are plotted (Fig. 6) to show the formation of the CAP, similar to the tether profiles in Fig. 3. Temperatures decreased at the most rapid rate from the beginning of the IOP (1900 UTC) until $1 \mathrm{~h}$ after sunset (2230 UTC). This rapid change in temperature marks the EET. Temperatures at the end of the EET appeared to remain highly dependent on slope aspect, as site $1 \mathrm{~S}$, site $6 \mathrm{~S}$, and site $10 \mathrm{~S}$ on the south-facing slope remained $2^{\circ}-4^{\circ} \mathrm{C}$ warmer than sites on the north-facing slope. Additionally, site $17 \mathrm{~N}$, located at the summit of the north-facing slope on relatively flat terrain, had a warmer temperature than the other north-facing sites at lower elevations, consistent with a nocturnal inversion. 


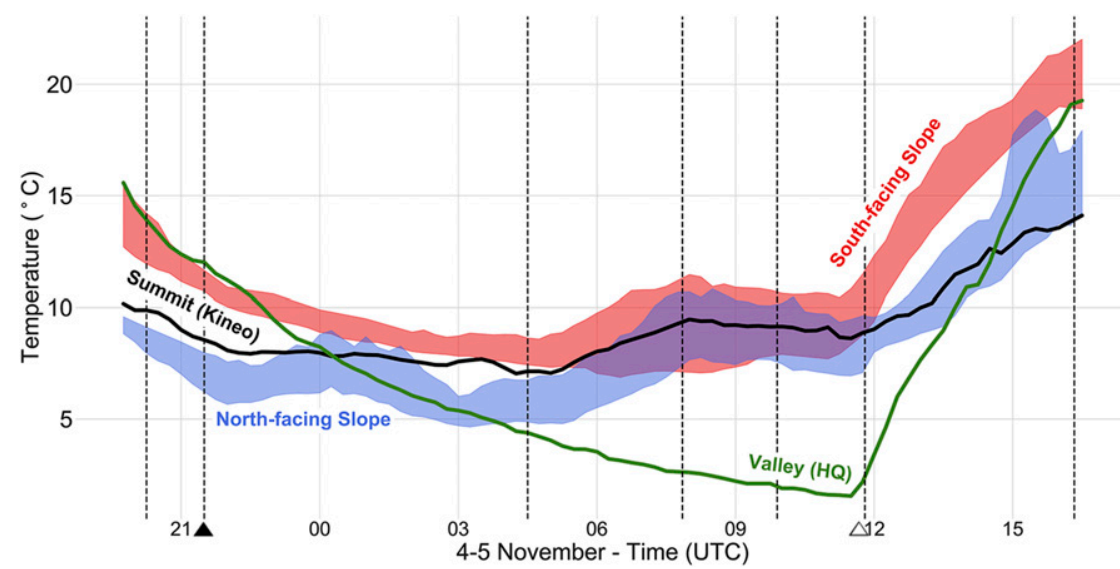

FIG. 6. Time series of summit (Kineo; $903 \mathrm{~m}$ ) and valley (HQ; $256 \mathrm{~m}$ ) temperatures and the temperature range on south-facing [sites 1S $(480 \mathrm{~m}), \operatorname{SCAN}(450 \mathrm{~m}), 6 \mathrm{~S}(727 \mathrm{~m})$, and $10 \mathrm{~S}$ $(693 \mathrm{~m})$ ] and north-facing [sites 14N (733 m), 17N (903 m), 19N (596 m), 23N (668 m), 24N $(817 \mathrm{~m})$, and MWS $(668 \mathrm{~m})]$ slopes. Kineo temperatures are from nearby site $17 \mathrm{~N}$. Dashed black vertical lines correspond to time delineations $1-6$ of section $3 \mathrm{~b}$. Filled and open triangles below the $x$ axis indicate sunset (2135 UTC) and sunrise (1127 UTC), respectively.

\section{2) 2130 UTC 4-0430 UTC 5 NOVEMBER}

After 2230 UTC, temperatures increased at sites $23 \mathrm{~N}$ and $24 \mathrm{~N}$, and a weaker and more brief warming occurred at sites $14 \mathrm{~N}$ and $17 \mathrm{~N}$ (Fig. 6) at the time of an $82 \%$ increase in wind speeds (from 0.9 to $1.7 \mathrm{~m} \mathrm{~s}^{-1}$ ) from the south at the Kineo tower (Fig. 5). As Kineo wind speeds increased and remained higher until 0030 UTC, katabatic wind speeds at the MWS decreased from 0.5-0.8 to 0.1$0.4 \mathrm{~m} \mathrm{~s}^{-1}$ from the SSW during 2230-0030 UTC. Warmer air near ridge altitude that feeds into the katabatic winds on the north-facing slope would lead to warmer, less negatively buoyant air, and slower katabatic winds.

MWS katabatic wind speeds increased to $0.8-1.0 \mathrm{~m} \mathrm{~s}^{-1}$ from the south (downslope) at 0230 UTC and decreased slightly to $0.5-0.7 \mathrm{~m} \mathrm{~s}^{-1}$ from the SSW (downslope) by 1130 UTC (sunrise) while Kineo wind speeds became northwesterly and increased from $\sim 1.1$ to $4.0 \mathrm{~m} \mathrm{~s}^{-1}$ during $0300-0800$ UTC and then decreased to $2.0 \mathrm{~m} \mathrm{~s}^{-1}$ just before sunrise. Wind speeds at site $1 \mathrm{~S}$ were similar to MWS all night except that it did not exhibit a decrease early in the night between 2200 and 0200 UTC. Wind at HQ became calm for most of the night after 0000 UTC. This disconnect between high- and low-elevation sites (Kineo and HQ, respectively) is also seen in the differing temperature trends (Fig. 6) and reveals the strong stability of the CAP and insensitivity of the bottom of the CAP to processes acting above the CAP.

\section{3) 0430-0751 UTC 5 NOVEMBER}

Between 0540 and 0605 UTC, strong warming $\left(2^{\circ}-4^{\circ} \mathrm{C}\right)$ reached all sites $\geq 596 \mathrm{~m}$ MSL, except site $10 \mathrm{~S}$ (Fig. 6red; broadening of temperature range). Katabatic wind speeds decreased by $0.1-0.3 \mathrm{~m} \mathrm{~s}^{-1}$ at site $1 \mathrm{~S}$, the MWS, and the SCAN site (Fig. 5) at the same time that the warming occurred at higher elevations, likely a response to the increased temperature of the source air of the katabatic flow as mentioned above. Site $23 \mathrm{~N}(668 \mathrm{~m})$ experienced warming just after 0600 UTC, but the south-facing site $10 \mathrm{~S}$ $(693 \mathrm{~m})$ at a similar elevation did not observe the same warming for another hour. Site $19 \mathrm{~N}(596 \mathrm{~m})$ on the northfacing slope observed its strongest warming at nearly the same time as site $10 \mathrm{~S}$. Site $1 \mathrm{~S}(480 \mathrm{~m})$ observed only slight warming at 0900 UTC. These data indicate that the warmer temperatures introduced via southwesterly WAA took longer to affect sites at lower elevations deep in the CAP and farther north on the slopes, possibly because of viscous drag of the southwest winds on the upper CAP creating a tilted CAP top that was higher on the southfacing slopes. HQ (256 m) was not affected by the warming aloft during the entire night (Fig. 6).

\section{4) AND 5) 0751-1148 UTC 5 NOVEMBER}

At 0800 UTC, the warming ended on the slopes, and temperatures remained steady or decreased slightly as radiational cooling began to dominate once more. Katabatic wind speeds at MWS returned to magnitudes more similar to before WAA occurred $\left(\sim 0.5 \mathrm{~m} \mathrm{~s}^{-1}\right)$, as Kineo tower wind speeds decreased steadily from 4 to $2 \mathrm{~m} \mathrm{~s}^{-1}$ between 0900 UTC and sunrise ( 1130 UTC) (Fig. 5). These responses are expected when WAA diminishes.

\section{6) 1148-1620 UTC 5 NOVEMBER}

Temperatures at HQ and on the south-facing slope warmed from insolation within $30 \mathrm{~min}$ after sunrise, and 
temperatures on the north-facing slope began to increase within an additional hour. Katabatic winds were observed on the south-facing slope until 1.5-2.0 $\mathrm{h}$ after sunrise, and continued on the north-facing slope for $3 \mathrm{~h}$ after sunrise. On the south-facing slope, anabatic winds began to form around 1330 UTC and strengthened thereafter. Although katabatic wind speeds were significantly higher at site $1 \mathrm{~S}$ than the lower elevation SCAN site, anabatic winds were of similar magnitude. Katabatic winds diminished and became calm on the north-facing slope (at the MWS) at 1430 UTC but did not turn anabatic prior to the end of the IOP (1630 UTC). The indirect sunlight on the north-facing slope was likely able to balance outgoing longwave radiation, but was too weak to initiate anabatic winds (Fig. 5).

\section{d. Subcanopy versus clearings}

Observations indicate differential cooling occurred vertically across the canopy level. Temperatures were $\sim 2^{\circ} \mathrm{C}$ colder in the $\sim 40 \mathrm{~m}$-diameter clearing at site $23 \mathrm{~N}$ than at the MWS under the canopy (Fig. 7). Using Kestrels, the authors stood in the middle of the clearing on the $\sim 1.5$-m-tall rain gauge platform to measure wind speed. Observed wind speeds at $\sim 3 \mathrm{~m}$ above ground were $50 \%$ faster in the clearing $\left(1.0 \mathrm{vs} 1.5 \mathrm{~m} \mathrm{~s}^{-1}\right)$. Additional manual observations of wind and temperature were made along the upslope edges of the clearings, and indicated that the edge of the clearing was slightly warmer (by $\sim 0.5^{\circ} \mathrm{C}$ ) and associated with weaker downslope winds in the subcanopy layer $\left(\sim 0.3-0.5 \mathrm{~m} \mathrm{~s}^{-1}\right)$. Given the small size of the clearing ( $\sim 40-\mathrm{m}$ diameter) and that subcanopy wind speeds upslope of the clearing were relatively weak $\left(\sim 1 \mathrm{~m} \mathrm{~s}^{-1}\right)$ and warmer (by $\sim 1^{\circ} \mathrm{C}$ ), the colder and faster winds measured in the clearing most likely originated from above the canopy. The inverse relationship between subcanopy temperature and wind speed at MWS (Fig. 8) supports this conclusion. Therefore, the coldest air formed on top of the canopy even with the scattered deciduous trees mostly defoliated, while the relatively warm ground and sheltering of the standing biomass maintained a warmer temperature below canopy. Colder, faster katabatic winds flowed on top of the canopy, while warmer, slower katabatic winds flowed underneath the canopy. This wind speed profile and unstable vertical profile was also observed by Pypker et al. (2007), which they found allowed turbulent mixing across the canopy layer. Turbulent mixing between the above and subcanopy layers at the MWS occurred throughout the night (Fig. 7). This relationship became stronger after 0530 UTC, when WAA commenced (correlation coefficient $r$ went from -0.82 to -0.97$)$. The average slope of the two linear regression lines is -0.21 , suggesting a $1^{\circ} \mathrm{C}$ decrease in ambient air temperature is associated with an increase in katabatic

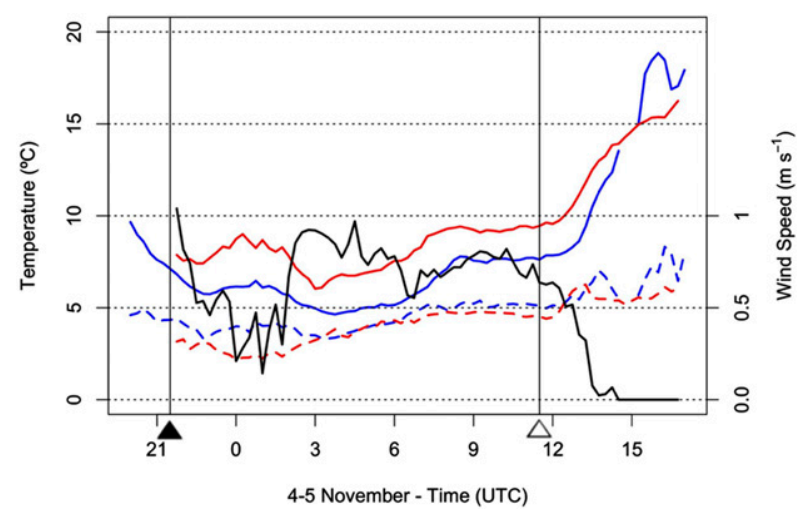

FIG. 7. Time series of 15-min-averaged temperature (solid blue line) and dewpoint temperature (dashed blue line) at site $23 \mathrm{~N}$ $(668 \mathrm{~m})$ and temperature (solid red line), dewpoint temperature (dashed red line), and wind speed (solid black line) at the adjacently located MWS below canopy. Vertical black lines with triangles below the $x$ axis indicate sunset (2135 UTC) and sunrise (1127 UTC).

wind speed under the canopy of $0.21 \mathrm{~m} \mathrm{~s}^{-1}$. These data suggest that a significant amount of subcanopy momentum originates from downward momentum flux of abovecanopy katabatic winds.

Although limited in number, point measurements of temperature and wind suggest this unstable thermal profile exists along sloping terrain, and not in the bottom of the valley. If the small canopy opening along the road and brook allows this cold air to easily sink down to the surface, then we would expect to observe a stronger wind at the bridge. In addition, the bridge site was $0.4^{\circ}-0.5^{\circ} \mathrm{C}$ warmer than $20 \mathrm{~m}$ north of the bridge for most of the night. Where this vertical stability transition occurs is poorly constrained by these data, but a likely location is along the slopes where the CAP top meets the canopy. This transition may also be associated with a transition from a downslope (katabatic) flow above the CAP to a mountain wind (along-valley) within the CAP, as observed, for example, by Vosper et al. (2014) and over a gentler slope by Bodine et al. (2009). Subcanopy air remained warmer until $\sim 1500$ UTC when insolation warmed the air in the openings more than within the partially shaded forest (Fig. 7).

\section{Discussion}

Katabatic winds had already commenced on the north-facing slope of HBEF when we arrived at site $23 \mathrm{~N}$ at $\sim 2130$ UTC 4 November 2015. Katabatic winds helped to rapidly deepen the CAP to $\sim 140 \mathrm{~m} \mathrm{ABL}$ by 2130 UTC. The maximum depth of the CAP likely never exceeded $140-150 \mathrm{~m}$ during the overnight period because of a dynamic equilibrium between the influx 


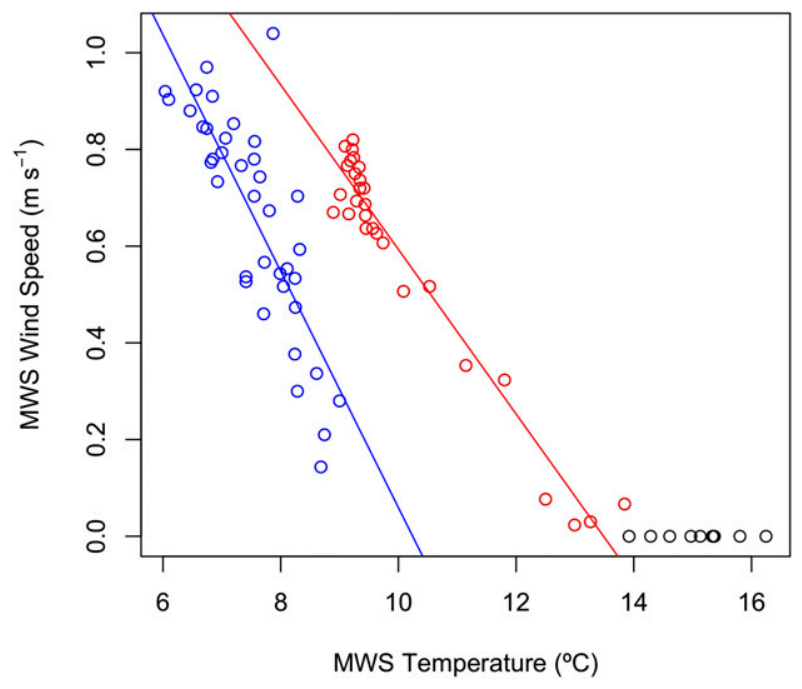

FIG. 8. MWS observed 15-min average air temperatures and katabatic wind speeds during 4-5 Nov 2015. Observations prior to the commencement of WAA at 0530 UTC are shown as blue circles, those after commencement of WAA are shown as red circles, and black circles represent data after 1430 UTC when katabatic winds ceased. Linear regression lines show the wind speed dependence on temperature before $(|\mathbf{V}|=-0.24 T+2.50$; correlation coefficient $r=-0.82)$ and after $(|\mathbf{V}|=-0.17 T+2.29$; $r=-0.97)$ WAA.

of cold air via katabatic winds and the drainage of the CAP (i.e., mountain wind) eastward into the Pemigewasset River valley. An equilibrium CAP top near $600 \mathrm{~m}$ MSL is suggested by several lines of evidence: 1 ) the relatively steady isentropic layer in the uppermost $15 \mathrm{~m}$ ( $\sim 588-603 \mathrm{~m} \mathrm{MSL})$ of the tethered-balloon profile that persisted for the first half of the night (Fig. 4), 2) katabatic winds at $668 \mathrm{~m}$ MSL at the MWS only experienced a decrease in wind speed with associated increased wind and temperature aloft (e.g., at Kineo) and a rapid warming trend commenced early at 0315 UTC, suggesting the CAP did not deepen to this next-highest site above the tethered balloon, and 3) the topography of HBEF that defines the CAP reservoir size and shape, and drainage area into the Pemigewasset River valley to the east. To elaborate on this last point, the HBEF topography favors a maximum CAP top near $600 \mathrm{~m}$ because of the $\sim 600 \mathrm{~m}$ MSL plateau to the north of the main Hubbard Brook channel (Fig. 1). The surface area within the valley is greatest around $600 \mathrm{~m}$ MSL (Fig. 9) indicating a large increase in volume per unit of elevation needed to be filled for the CAP to continue to grow. The katabatic wind influx must significantly exceed the eastward drainage of cold air to be able to fill the broad region above the plateau. Furthermore, as CAP height exceeds $\sim 600 \mathrm{~m} \mathrm{MSL}$, the width of the drainage flow would expand farther southeast over the

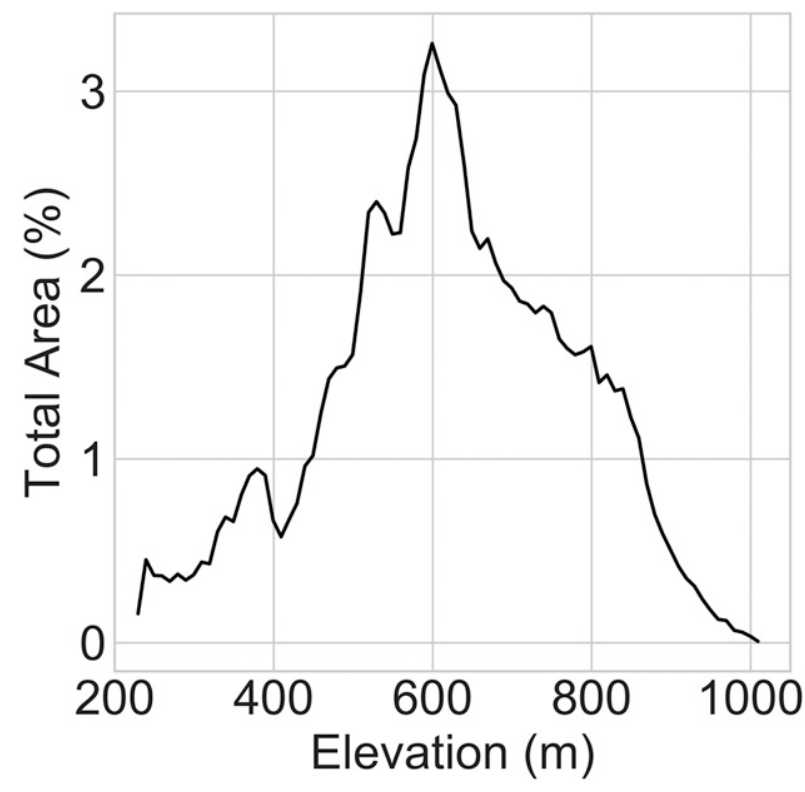

FIG. 9. Percent of the total area within HBEF for a given elevation band of $10 \mathrm{~m}$.

ridgeline, as noted by the orange arrow in Fig. 10. Thus, the outflow rate would increase, and in the absence of any mechanism to increase katabatic inflow, the CAP depth would decrease until the inflow and outflow returned to an equilibrium. The low col on the northwest border of HBEF at just over $600 \mathrm{~m}$ MSL is another potential outflow channel if the CAP were to exceed $600 \mathrm{~m}$ MSL; observations in the col are needed to discover the nature of airflow in this area.

Slope temperatures are highly dependent on slope aspect in the early stages of CAP formation, and these differences continue through the entire night. Southfacing slopes had higher temperatures than north-facing slopes, regardless of elevation. Sites $14 \mathrm{~N}(733 \mathrm{~m})$ and $6 \mathrm{~S}$ $(727 \mathrm{~m})$, and sites $23 \mathrm{~N}(668 \mathrm{~m})$ and $10 \mathrm{~S}(693 \mathrm{~m})$ experience substantially different temperatures, despite being at similar elevations. Sites $6 \mathrm{~S}$ and $10 \mathrm{~S}$ on the southfacing slope are $\sim 5^{\circ} \mathrm{C}$ warmer at the beginning of the night and between $0^{\circ}$ and $2^{\circ} \mathrm{C}$ warmer by the end of the night than their north-facing slope counterparts, sites $14 \mathrm{~N}$ and $23 \mathrm{~N}$. These temperature differences reflect the significant insolation differences between the southfacing slopes and the north-facing slopes and the ability of the biomass to retain this heat through most of the night.

Low-level WAA influenced the rapid increase in CAP intensity between 0800 and 1100 UTC. Turbulent mixing initially transported warm air $\sim 15 \mathrm{~m}$ downward through the observed vertical profile at 0830 UTC, then an additional $50 \mathrm{~m}$ at $\sim 1000 \mathrm{UTC}$. This upper layer was most prone to erosion because of its relatively low static 

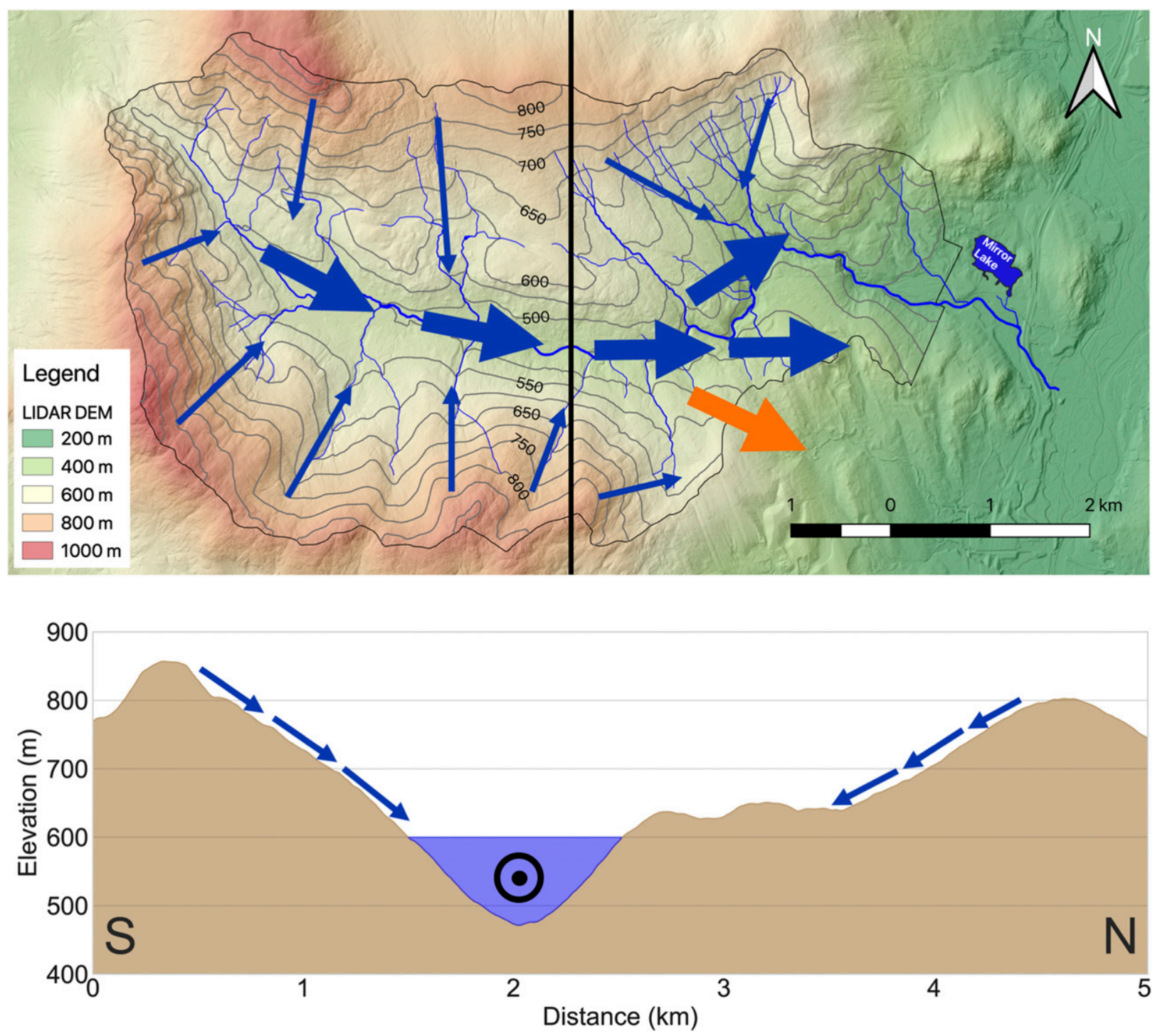

FIG. 10. Schematic diagram of drainage flows during maximum observed CAP height in HBEF. Small blue arrows represent katabatic wind flow. Large blue arrows represent the mountain wind (drainage flow) through the CAP; the large orange arrow represents the increased drainage that will occur to the southeast if CAP height were to increase above $600 \mathrm{~m}$ MSL. The vertical black line shows the location of the vertical cross section in the bottom panel.

stability at the top of the inversion shown by the $\theta_{v}$ profiles (Fig. 4). The overall static stability of the CAP significantly increased with the WAA, as shown by the CPI increasing from 11 to $15 \mathrm{~K}$ (Fig. 3a). The upper $\sim 30-40 \mathrm{~m}$ of the tethered temperature profile remained in the warm air above the CAP during the last significant cooling $(\sim 2 \mathrm{~K})$ in the upper CAP around 1130 UTC. The cooling may have been caused by a return of katabatic winds replenishing the CAP and/or a seiche. Both are favorable since the wind speeds in the warm air above the CAP decreased (e.g., Kineo, Fig. 5). The calmer conditions on the slopes above the CAP would also lead to a resumption of katabatic inflow to cool and grow the CAP. The southwesterly wind would also favor pushing the CAP up the south-facing slope as suggested by the lagged warming on the south-facing slope sites. As the winds decreased along the CAP top, a seiche might commence with the cold air sloshing back to the south and effectively increasing the CAP depth at the site of the tethered balloon, but the occurrence of a seiche and its role in CAP depth and temperature profile along the tethered balloon is speculative.

This CAP event can be classified as a combined upperdisturbance and layered erosion event based on the classifications of Dorninger et al. (2011). WAA served as the upper disturbance that eroded the upper layer of 
the CAP. Wind speeds above the CAP weakened after the initial surge of WAA, which, in combination with an increase in stability (e.g., Brunt-Väisälä frequency increased by $\left.0.5 \mathrm{~s}^{-1}\right)$, prevented additional dynamical erosion (Petkovsek 1992; Rakovec et al. 2002; Zhong et al. 2003).

The $\sim 0600$ UTC warming was weaker and delayed by $2 \mathrm{~h}$ at site $1 \mathrm{~S}$ relative to the MWS (Fig. 5). Warming at site $6 \mathrm{~S}$ was significant $\left(3^{\circ} \mathrm{C}\right)$ and occurred at the same time as the decrease in katabatic wind speed downslope at site $1 \mathrm{~S}$. Therefore, WAA near the top of the slopes as evidenced at sites $6 \mathrm{~S}$ and $17 \mathrm{~N}$ (Fig. 6) was strong enough to weaken the katabatic flow at lower elevations as observed at site $1 \mathrm{~S}$ and SCAN (Fig. 5).

Katabatic wind speeds at site $1 \mathrm{~S}$ and the MWS were relatively similar for most of the night, despite the MWS remaining above the CAP and site $1 \mathrm{~S}$ located within the CAP. The differences in local topography and forest structure may explain this unexpected observation. Site $1 \mathrm{~S}$ is located in a $\sim 40-\mathrm{m}$ clearing of northern hardwood forest, while the MWS is surrounded by a hardwood-spruce-fir mixed forest. Both sites are on $17^{\circ}$ slopes. Kestrel wind speed measurements at the MWS were $50 \%$ lower $\left(2 \mathrm{vs} 1 \mathrm{~m} \mathrm{~s}^{-1}\right)$ than the adjacently located site $23 \mathrm{~N}$, likely because of friction from the understory. Site $1 \mathrm{~S}$ wind speeds were comparable or slightly weaker in both the clearing and under adjacent canopy, respective to site $23 \mathrm{~N}$, likely because of heat retention on the south-facing slope creating a weaker density gradient with the air located over the valley. Additionally, site $1 \mathrm{~S}$ was located within the CAP where negative buoyancy of katabatic flow is weak, and some component of the katabatic wind is likely directed horizontally over the CAP as the air encounters layers of higher stability (Fig. 4; Bodine et al. 2009; Vosper et al. 2014). In contrast to these studies, the concurrent timing of a slowing of wind speeds at sites $6 \mathrm{~S}$ and $1 \mathrm{~S}$ imply a connection and the possibility that some katabatic flow from above the CAP penetrates down into the CAP. It could be that only the subcanopy branch of katabatic flow directly penetrates into the subcanopy CAP, but more observations are needed.

After sunrise ( $\sim 1130$ UTC) insolation terminated the formation of katabatic winds on the south-facing slopes. This process allowed the CAP to drain into the Pemigewasset River valley to the east and insolation eroded the CAP from the bottom (on the south-facing slopes), thus reducing CAP height. The airmass became isentropic above canopy by the end of the IOP at $\sim 1620$ UTC, but a weak stable layer remained below canopy (inferred in Fig. 3) suggestive that the canopy sheltered this cool stable air from insolation, as seen also at H. J. Andrews Experimental Forest (Pypker et al. 2007).
The study presented here is from one CAP formation event in HBEF and therefore, the generalizations to be made from our analysis are minimal. The timing and/or duration of some processes, such as the length of time required for the CAP to reach its maximum depth, might vary with seasonal environmental changes, which cannot be resolved here. Despite these limitations, some processes observed or suggested by the data are likely to be common features during relatively clear and calm nights in HBEF, which typically occur multiple times each month. First, numerous lines of evidence support an upper limit to CAP depth near $600 \mathrm{~m}$ MSL in HBEF, as described at the beginning of this section. Second, the slope measurements of temperature and wind in clearing and under the canopy suggest stronger and colder flow above canopy than subcanopy. This type of split katabatic flow was conclusively observed on a sloped site in a forest with similar stature, although with more foliage, at H.J. Andrews Experimental Forest (Pypker et al. 2007). Related to this, the canopy is likely the effective radiative surface cooling the air despite patchy foliage, as is supported by the observations of Pypker et al. (2007). Last, air temperature in clearings along a mountain slope is colder than in the subcanopy. Whether the cause is in situ radiative cooling and/or katabatic wind advection from above the canopy is yet to be conclusively shown, but this observation could have important implications for microecosystems emerging after a disturbance creates a significant opening in the forest canopy.

\section{Conclusions}

This study investigated the evolution of a diurnal CAP in the Hubbard Brook Experimental Forest valley between 4 and 5 November 2015. A tethered balloon equipped with $31 \mathrm{HOBO}$ dataloggers was used to observe a $150-\mathrm{m}$ vertical temperature profile at $\sim 5 \mathrm{~m}$, 30 -s resolution, aided by surface measurements from a mobile weather station, a network of temperature sensors within HBEF, and manual weather observations on the north and south-facing slopes. The CAP initially developed under the influence of radiational cooling and katabatic winds. During the early overnight period, synoptic-scale WAA acted as an upper-level disturbance to the CAP, caused a $6^{\circ} \mathrm{C}$ increase in the CPI and an increase in static stability. Turbulent mixing associated with WAA eroded the upper CAP about halfway through the night and created a shallower CAP with high static stability. WAA subsided prior to 1130 UTC, presenting a brief window during which the CAP was able to deepen again, before eroding following sunrise. 
The key findings of this case study are as follows:

1) CAP formation occurred rapidly and the maximum CAP depth was likely achieved by sunset. This phase is consistent with the EET identified by Acevedo and Fitzjarrald (2001).

2) CAP depth in HBEF likely has an upper limit around $600 \mathrm{~m}$ MSL that is dictated by the shape of the valley.

3) The WAA disturbance eroded the upper part of the CAP for nearly $4 \mathrm{~h}$, but the CAP was able to cool and deepen again as soon as the winds above the CAP began to weaken.

4) Observations suggest that the canopy acts as the most effective radiating surface at night, which leads to a split katabatic flow where colder and faster katabatic flow occurs above the canopy (as also observed by Pypker et al. 2007).

Despite significant seasonal leaf loss, the mixed-forest canopy was enough of a barrier to separate these colder katabatic winds from warmer and slower katabatic winds under the canopy. Periodic mixing of these two katabatic flows was observed, resulting in downward positive momentum and negative heat fluxes. Moisture fluxes may also be implicated, but was not addressed in this study. The importance of these fluxes, especially of the contributions of the heat and momentum fluxes to the subcanopy katabatic flow, requires further investigation and could have significant implications for eddy covariance calculations in areas of sloping terrain.

Our results suggest that these vertical gradients and vertical fluxes through the canopy nearly vanish within the CAP, but a dense vertical transect of observations in this hypothesized transition zone is required in future work to understand the subcanopy and above-canopy thermal and dynamic transitions through the top of the CAP.

The influence of WAA on the strength and stability of the CAP has applications to cold-air-damming events, air quality, elevation-dependent climate, and forest fire management, where stable surface layers are enhanced by strong warm-air advection above. Future investigations should include wind measurements along the vertical profile to examine heat flux, stability, and Froude number.

Heat retention by the forest biomass resulted in an isentropic layer within the forest canopy that resulted in surface temperatures $\sim 1^{\circ}-2^{\circ} \mathrm{C}$ warmer than in clearings and above the canopy. Turbulent mixing via periodic downward momentum flux through the canopy and friction with the ground and biomass may have significant contributions to the maintenance of this subcanopy isentropic layer. Future studies could observe this phenomenon with a combination of wind observations and infrared cameras within clearings and canopied areas.
Acknowledgments. The Plymouth State University Department of Atmospheric Science and Chemistry and Judd Gregg Meteorology Institute provided a majority of the instrumentation and supplies used in this field study. The authors thank the U.S. Forest Service staff at the Hubbard Brook Experimental Forest for permitting us to conduct our field experiment. We personally thank Brendon Hoch [formerly at the Pennsylvania State University (PSU) and now at Cold Regions Research and Engineering Laboratory in Hanover, New Hampshire] for providing technical and logistical support for the field research and Dr. Dennis Machnik of PSU for providing the balloon lighting.

\section{REFERENCES}

Acevedo, O. C., and D. R. Fitzjarrald, 2001: The early evening surfacelayer transition: Temporal and spatial variability. J. Atmos. Sci., 58, 2650-2667, https://doi.org/10.1175/1520-0469(2001)058<2650: TEESLT $>2.0 . \mathrm{CO} ; 2$.

Bell, G. D., and L. F. Bosart, 1988: Appalachian cold-air damming. Mon. Wea. Rev., 116, 137-161, https://doi.org/10.1175/15200493(1988)116<0137:ACAD>2.0.CO;2.

Bodine, D., P. M. Klein, S. C. Arms, and A. Shapiro, 2009: Variability of surface air temperature over gently sloped terrain. J. Appl. Meteor. Climatol., 48, 1117-1141, https://doi.org/ 10.1175/2009JAMC1933.1.

Bowling, D. R., S. P. Burns, T. J. Conway, R. K. Monson, and J. W. C. White, 2005: Extensive observations of $\mathrm{CO}_{2}$ carbon isotope content in and above a high-elevation subalpine forest. Global Biogeochem. Cycles, 19, 149-166, https://doi.org/ 10.1029/2004GB002394.

Clements, C. B., C. D. Whiteman, and J. D. Horel, 2003: Cold-airpool structure and evolution in a mountain basin: Peter Sinks, Utah. J. Appl. Meteor., 42, 752-768, https://doi.org/10.1175/ 1520-0450(2003)042<0752:CSAEIA > 2.0.CO;2.

Dorninger, M., C. D. Whiteman, B. Bica, S. Eisenbach, B. Pospichal, and R. Steinacker, 2011: Meteorological events affecting coldair pools in a small basin. J. Appl. Meteor. Climatol., 50, 22232234, https://doi.org/10.1175/2011JAMC2681.1.

Gustavsson, T., M. Karlsson, J. Bogren, and S. Lindqvist, 1998: Development of temperature patterns during clear nights. J. Appl. Meteor., 37, 559-571, https://doi.org/10.1175/15200450(1998)037<0559:DOTPDC>2.0.CO;2.

Iijima, Y., and M. Shinoda, 2000: Seasonal changes in the coldair pool formation in a subalpine hollow, central Japan. Int. J. Climatol., 20, 1471-1483, https://doi.org/10.1002/10970088(200010)20:12<1471::AID-JOC554>3.0.CO;2-6.

Katurji, M., and S. Zhong, 2012: The influence of topography and ambient stability on the characteristics of cold-air pools: A numerical investigation. J. Appl. Meteor. Climatol., 51, 17401749, https://doi.org/10.1175/JAMC-D-11-0169.1.

Kiefer, M. T., and S. Zhong, 2013: The effect of sidewall forest canopies on the formation of cold-air pools: A numerical study. J. Geophys. Res. Atmos., 118, 5965-5978, https:// doi.org/10.1002/jgrd.50509.

Lareau, N. P., E. Crosman, C. D. Whiteman, J. D. Horel, S. W. Hoch, W. O. J. Brown, and T. W. Horst, 2013: The persistent cold-air pool study. Bull. Amer. Meteor. Soc., 94, 51-63, https://doi.org/ 10.1175/BAMS-D-11-00255.1. 
Mahrt, L., and R. Heald, 2015: Common marginal cold pools. J. Appl. Meteor. Climatol., 54, 339-351, https://doi.org/10.1175/ JAMC-D-14-0204.1.

Malek, E., T. Davis, R. Martin, and P. Silva, 2006: Meteorological and environmental aspects of one of the worst national air pollution episodes (January, 2004) in Logan, Cache Valley, Utah, USA. Atmos. Res., 79, 108-122, https://doi.org/10.1016/ j.atmosres.2005.05.003.

Petkovsek, Z., 1992: Turbulent dissipation of cold air lake in a basin. Meteor. Atmos. Phys., 47, 237-245, https://doi.org/ 10.1007/BF01025620.

Pypker, T. G., M. H. Unsworth, B. Lamb, E. Allwine, S. Edburg, E. Sulzman, A. C. Mix, and B. J. Bond, 2007: Cold air drainage in a forested valley: Investigating the feasibility of monitoring ecosystem metabolism. Agric. For. Meteor., 145, 149-166, https://doi.org/10.1016/j.agrformet.2007.04.016.

Rakovec, J., J. Merše, S. Jernej, and B. Paradiž, 2002: Turbulent dissipation of the cold-air pool in a basin: Comparison of observed and simulated development. Meteor. Atmos. Phys., 79, 195-213, https://doi.org/10.1007/s007030200003.

Schmidli, J., and R. Rotunno, 2010: Mechanisms of alongvalley winds and heat exchange over mountainous terrain. J. Atmos. Sci., 67, 3033-3047, https://doi.org/10.1175/ 2010JAS3473.1.

Simms, M. M., 2017: A sensitivity analysis of WRF-simulated cold air damming using variable parameterization schema. M.S. Applied Meteorology Thesis, Plymouth State University, 131 pp., https://digitalcommons.plymouth.edu/etd/149/.

Steiger, R., and M. Mayer, 2008: Snowmaking and climate change: Future options for snow production in Tyrolean ski resorts. Mt. Res. Dev., 28, 292-298, https://doi.org/10.1659/ mrd.0978.

Sun, H., T. L. Clark, R. B. Stull, and T. A. Black, 2006: Twodimensional simulation of airflow and carbon dioxide transport over a forested mountain. Part II: Carbon dioxide budget analysis and advection effects. Agric. For. Meteor., 140, 352-364, https:// doi.org/10.1016/j.agrformet.2006.03.016.

Vosper, S. B., J. K. Hughes, A. P. Lock, P. F. Sheridan, A. N. Ross, B. Jemmett-Smith, and A. R. Brown, 2014: Cold-pool formation in a narrow valley. Quart. J. Roy. Meteor. Soc., $\mathbf{1 4 0}$, 699-714, https://doi.org/10.1002/qj.2160.

Whiteman, C. D., S. Zhong, and X. Bian, 1999b: Wintertime boundary layer structure in the Grand Canyon. J. Appl. Meteor., 38, 1084-1102, https://doi.org/10.1175/1520-0450(1999) $038<1084$ :WBLSIT $>2.0$.CO;2.

,-- W. J. Shaw, J. M. Hubbe, X. Bian, and J. Mittelstadt, 2001: Cold pools in the Columbia Basin. Wea. Forecasting, 16, 432-447, https://doi.org/10.1175/1520-0434(2001)016<0432: CPITCB $>2.0 . \mathrm{CO} ; 2$.

_ S. W. Hoch, J. D. Horel, and A. Charland, 2014: Relationship between particulate air pollution and meteorological variables in Utah's Salt Lake Valley. Atmos. Environ., 94, 742-753, https://doi.org/10.1016/j.atmosenv.2014.06.012.

Wolf, T., I. Esau, and J. Reuder, 2014: Analysis of the vertical temperature structure in the Bergen valley, Norway, and its connection to pollution episodes. J. Geophys. Res. Atmos., 119, 10 645-10 662, https://doi.org/10.1002/2014JD022085.

Zhong, S., X. Bian, and C. D. Whiteman, 2003: Time scale for coldair pool breakup by turbulent erosion. Meteor. Z., 12, 229-233, https://doi.org/10.1127/0941-2948/2003/0012-0231. 